\title{
Emotional Intelligence and Its Association with Social Physique Anxiety and Performance among Sprinters
}

\author{
Devdeep Chakarvarti \\ Academic Heights Public School, Haridwar , Uttarakhand, India \\ Manohar Lal \\ Lovely Professional University, Phagwara, Punjab, India
}

\begin{abstract}
The present study was conducted to determine the relationship of emotional intelligence with social physique anxiety and performance of sprinters. It compared the emotional intelligence and social physique anxiety between high performance and low performance sprinters. The study was conducted with of 23 sprinters, including the high performers $\left(\mathrm{N}_{1}=8\right)$ and low performers $\left(\mathrm{N}_{2}=15\right)$ belonging to All India InterUniversity. To determine the relationship of emotional intelligence with social physique anxiety and performance, the product moment method of correlation was used, and to test the difference of significance between two groups independent ' $t$ ' test was used. The results revealed that all the components of emotional intelligence have negative insignificant relationship with social physique anxiety and competition performance among sprinters. The findings further showed that high performance sprinters were more emotionally intelligent with less social physique anxiety than low performance sprinters.
\end{abstract}

Key Words: Emotional intelligence, social physique anxiety, performance and sprinters.

\section{Introduction}

Sports of any kind, whether physical or mental, is a performance by an individual. This is never stable and is influenced by a number of factors. The present day sports setup is very organized and for almost every sport, physical or mental, an individual or team is supported by a complete team, which usually includes coaches, physical trainers, doctor and a sports psychologist. Though most of the other team members have been a part of the supporting a team for quite some time, the inclusion of sports psychologist has been made only in the recent past. The inclusion of sports psychologists coincides with the recent advances in the human psychology; efforts were made to find answers to some questions which remained unanswered through traditional approaches.

The emergence of concept of emotional intelligence is the result of such efforts. So, having recognized emotional intelligence as an important variable of human psychology which drives an individual and affects his performance in any concerned field, it becomes imperative to see how this variable correlates with the performance in sports, as these are not only intense but are full of aggression. Austin, E.J., et al., (2004) et al and Petrides, K et al. (2007) has underlined the importance of emotional intelligence, and it is put forwards to develop connection with adaptive mental working (Kirk et al., 2008). Measures of emotional intelligence associate with effective execution in various associated settings (Van Roy and Viswesvaran, 2004). They also find the 
relationship of emotional intelliegence with various variables of wellbeing and minimizing the impacts of anxiety (Schulte et al., 2007).

There is a developing enthusiasm for emotional intelligence in game (Meyer and Zizith, 2007). Latest investigation discovered emotional intelligence identified with feelings experienced ahead of fruitful and failed execution (Lane et al., 2009b). They found that feelings relating with fruitful execution are power, joy, and serenity, though feelings taking up with poor execution incorporate disarray, sorrow and exhaustion. Emotional intelligence connected absolutely with wonderful feelings and contrarily with offensive feelings. Lane et al (2009c) has been further discovered that scores of emotional intelligence corresponded with continuous utilization of mental abilities. Competitors announced regular utilization of mental aptitudes (Thomas et al., 1999) and additionally in self-report emotional intelligence scale they report high score (Schulte et al., 1998).

One of the belief regarding the self-consciousness is Social Physique Anxiety. SPA is the nervousness which happens as "an after effect of the possible EI level. SPA is highly relevant to one's physical self dissatisfaction; members who were disappointed with their self image perceived more SPA. Actually, it is suspected that SPA is directly associated to emotion with different approaches. In light of this, SPA may be connected with EI and also affect performance.

Leary (1992) established that self-presentation affected one's decision of activity environment, as people who tended to assess other's impression of their constitution in a negative way, maintained a strategic distance from activity, in which they have to display their physique (i.e. jogging areas, dance classes and swimming pools). This apprehension of refusing selfrecognition brought about entire non-participation in activity to lessen or put out the pain of social anxiety.

Hart, L. and Rijeka (1989) characterized this uneasiness as social physique anxiety (SPA), or emotions of tension as a consequence of having one's physical make-up assessed by others. SPA is a subordinate of social nervousness specifically identified with the reactions of the social judgment of one's build (Hart et al., 1989). Hart and associates (1989) operationally described the physique as "one's body shape and structure, particularly muscle to fat ratio ratios, muscle tone, and general body extents." These restless emotions are because of the social surrounding of activity, subsequently making nervousness identified with self-presentation and having one's body in plain view (Crawford \& Elkland, 1994).

Hausenblas, B., and Van R. (2004) established that for the individuals who might require confidence in their own self picture, maybe perceiving overweight or inediquate muscle tone, experienced emotions of unstable and demoralization in regards to practice investment. The inverse was likewise discovered to be valid as the individuals who saw themselves as being physically fit and having a slim constitution appreciated taking an interest in activity.

The present piece of research was carried out in pursuance to find the coorelation of emotional intelligence with social physique anxiety and competition performance of sprinters. In addition, difference between high performance and low performance sprinters were also identified.

\section{Methods and Procedure}

The present study was conducted through descriptive method of research and coorelational research design was used. Purposive random sampling procedure was adopted by the investigator 
for the collection of the data. The sample comprised of 23 sprinters, including the high performers $\left(\mathrm{N}_{1}=8\right)$ and low performers $\left(\mathrm{N}_{2}=15\right)$. Subjects age ranged between 18 and 28 years. Data was collected during the All India Inter-university championship held at Rajiv Gandhi University of Health Science, Jayanagar, Bangulore, w.e.f 16-01-2015 to 20-01-2015. The inventory of emotional intelligence developed by S. K. Mangal and Shubhra, Mangal (2004) was used to measure the emotional intelligence. This inventory consists of 100 items, which is further divided in four areas, each consists of 25 questions as; intra-personal awareness, inter-personal awareness, Intrapersonal management and Inter-personal management. Social physique anxiety was assessed by using 12 items scale developed by Hart, Leary, \& Rijeka (1989). For the analysis of data SPSS version 16 was used. In order to examine the correlation of emotional intelligence with social physique anxiety and performance, product moment method of correlation was used, and to test the difference of significance between two groups independent ' $t$ ' test was applied.

\section{Result and Discussion}

The present scientific investigation is a cross-sectional study of sprinters. In the present investigation, the relationship of emotional intelligence with social physique anxiety and performance has been investigated and then compared with high performers and low performers. The data collected by adopting above procedure were statistically analyzed. The results were presented in the following table.

Table-I: Association of emotional intelligence with social physique anxiety among sprinters $(\mathrm{N}=23)$

\begin{tabular}{|c|c|c|}
\hline Sr. No & Variable correlated with social physique anxiety & Co-efficient of correlation \\
\hline 1 & Intra-personal awareness & -.214 \\
\hline 2 & Inter-personal awareness & -.083 \\
\hline 3 & Intra-personal management & -.360 \\
\hline 4 & Inter-personal management & -.265 \\
\hline
\end{tabular}

*Significant at .05 level ( $\mathrm{r}=.423)$

Table-I revealed that all the 4 correlations of emotional intelligence components and social physique anxiety were insignificant. Social physique anxiety were insignificantly and negatively related to Intra-personal awareness $(\mathrm{r}=-.214)$, Inter-personal awareness $(\mathrm{r}=-.083)$, Intra-personal management $(\mathrm{r}=-.360)$, and Inter-personal management $(\mathrm{r}=-.265)$ among the sprinters.

From the analysis of the results, it is clear from the above table that the co-efficient of correlation of intra-personal awareness, inter-personal awareness; intra-personal management and inter-personal management have an insignificant and negative relationship with social physique anxiety among sprinters at .05 level of confidence. It shows that all components of emotional intelligence were negatively associated with the social physique anxiety among the sprinters. Results of present investivation did not coincide with the results reported by Lu FJ et al. (2010), they found that among track and field athletes, the components of emotional intelligence such as intrapersonal EI, and interpersonal EI is significantly associated with precompetitive 
anxiety. However, Mayer and Salvoes (2013) have found that Students whom engaged in all kinds of sports activities, have reported high social physique anxiety and more emotionally intelligent.

Table-II: Association of emotional intelligence with competition performance among sprinters $(\mathrm{N}=23)$

\begin{tabular}{|c|c|c|}
\hline Sr. No & $\begin{array}{c}\text { Variable correlated with competition } \\
\text { performance }\end{array}$ & Co-efficient of correlation \\
\hline 1 & Intra-personal awareness & -.182 \\
\hline 2 & Inter-personal awareness & -.108 \\
\hline 3 & Intra-personal management & -.022 \\
\hline 4 & Inter-personal management & -.128 \\
\hline
\end{tabular}

*Significant at .05 level ( $\mathrm{r}=.423)$

Table-II revealed that all the 4 correlations of emotional intelligence sub scales and competition performance were insignificant. Competition performance was insignificantly and negatively related to Intra-personal awareness $(\mathrm{r}=-.182)$, Inter-personal awareness $(\mathrm{r}=-.108)$, Intra-personal management $(\mathrm{r}=-.022)$, and Inter-personal management $(\mathrm{r}=-.128)$ among the sprinters.

The findings of the present study from the above table indicated the negative insignificant relationship between intra-personal awareness, inter-personal awareness, intra-personal management and inter-personal management with performance in sprinters at .05 level of confidence. It shows that all components of emotional intelligence were negatively associated with the competitive performance of the sprinters. Findings of Totterdell and Leach, (2001) are not in line with the findings of the present study. They found that among athletes, emotional regulation can prompt optimal performance. Wonderful feelings connected with Optimal execution and disagreeable feelings with broken execution (Andrew ML et al. 2010).

Table-III: Comparison of emotional intelligence between high performance and low performance sprinters

\begin{tabular}{|c|c|c|c|c|c|}
\hline Position & N & Mean & S.D & S.E.M & t-Value \\
\hline $\begin{array}{c}\text { High Performance } \\
\text { Sprinters }\end{array}$ & 8 & 55.25 & 6.71 & 2.37 & \\
\hline $\begin{array}{c}\text { Low Performance } \\
\text { Sprinters }\end{array}$ & 15 & 51.25 & 4.80 & 1.69 & 1.37 \\
\hline
\end{tabular}

Significant at .05 level ( $\mathrm{t}=\mathbf{2 . 0 8})$

Table-III depicted the mean and standard deviation values of emotional intelligence among high performance sprinters and low performance sprinters. The mean value of high performance sprinters is 55.25 and low performance sprinters is 51.25 . The calculated t- value (1.37) was less than the tabulated value (2.08), indicates that there was an insignificant difference in emotional 
intelligence between high performance and low performance sprinter. The graphical representation for the same is also given in fig-1

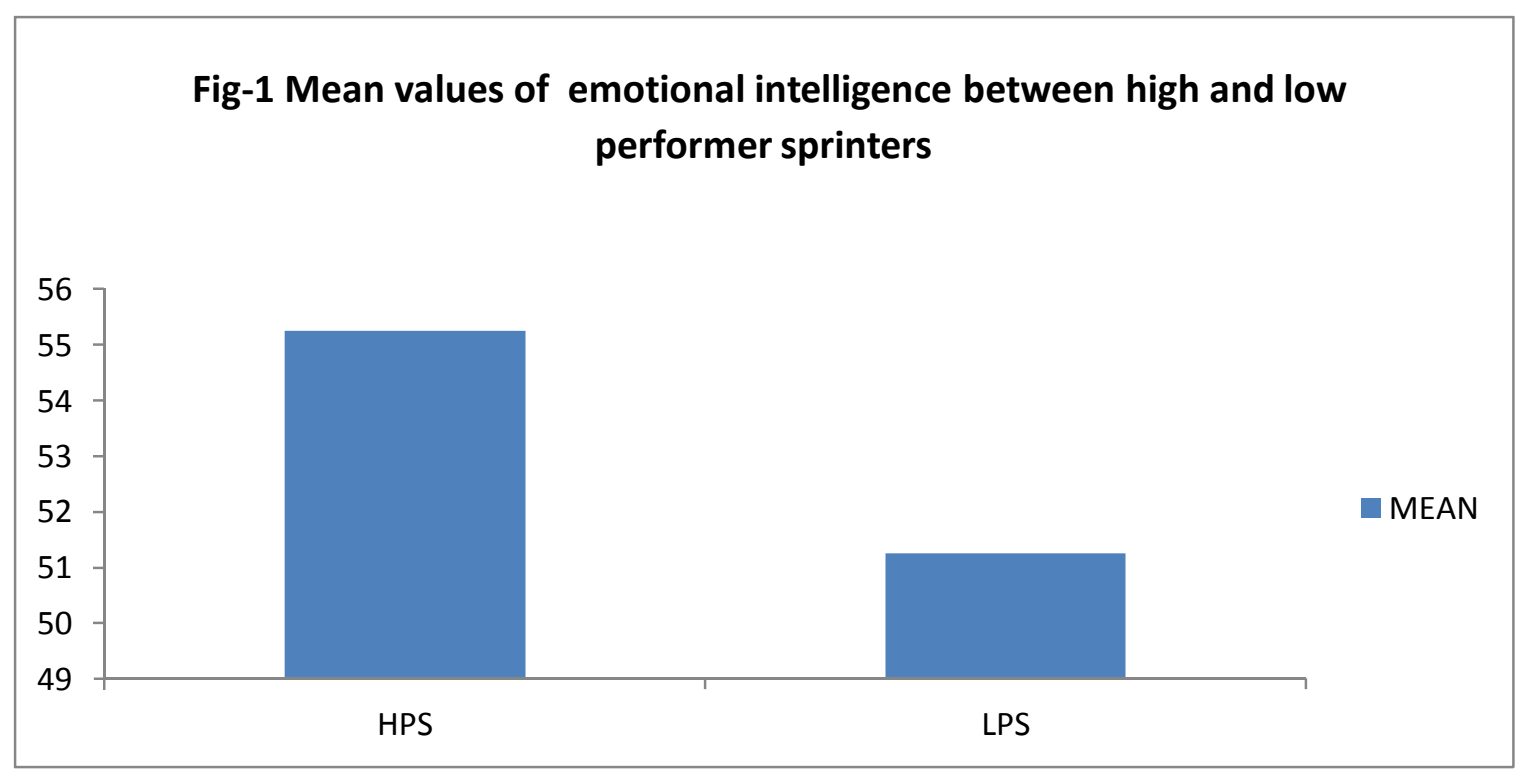

${ }^{*} \mathrm{HPS}=$ High performance sprinters, LPS= Low performance sprinters

It has been observed from the table-III, that high performance sprinters were emotionally more intelligent than low performance sprinters. This shows that emotional intelligence plays discriminate role in a performance, as high performers constantly control and manage their emotions under different conditions of competition. However, there were exist insignificant differences between high performers and low performers sprinters. The results of the present study are in line with the results of Frazee Zamanian et al (2011). They found that emotional intelligence is higher in elite athletes than non-athletes.

Table-IV: Comparison of social physique anxiety between high performance and low performance sprinters

\begin{tabular}{|c|c|c|c|c|c|}
\hline Position & N & Mean & S.D & S.E.M & t-Value \\
\hline $\begin{array}{c}\text { High Performance } \\
\text { Sprinters }\end{array}$ & 8 & 33.87 & 4.47 & 1.58 & \\
\hline $\begin{array}{c}\text { Low Performance } \\
\text { Sprinters }\end{array}$ & 15 & 28.5 & 3.83 & 1.35 & $2.58^{*}$ \\
\hline
\end{tabular}

*Significant at .05 level ( $\mathrm{t}=2.08)$

Table-IV depicted the mean and standard deviation values of social physique anxiety among high performance and low performance sprinters. The mean value of high performance sprinters is 28.5 and low performance sprinters is 33.87 . The calculated t-value (2.58) is more than tabularize value (2.08) at .05 level of confidence, which indicates that significant difference was exist in social physique anxiety between high performance and low performance sprinters. The graphical representation for the same is also given in fig-II. 


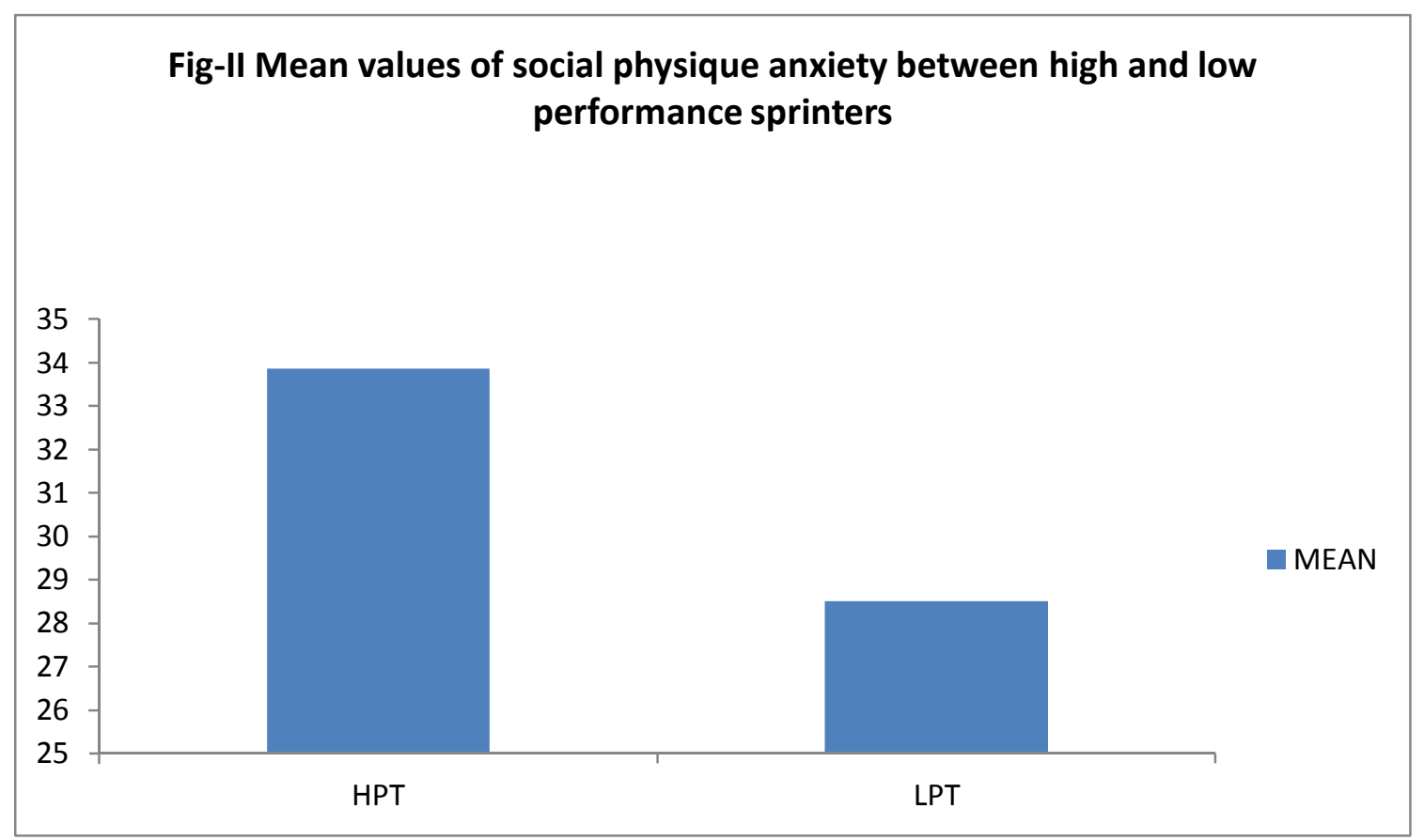

${ }^{*} \mathrm{HPS}=$ High performance sprinters, LPS= Low performance sprinters

It has been revealed from the table-IV, that high performance sprinters have less social physique anxiety than low performance sprinters. It indicates that social physique anxiety affects competition performance. Significant difference was also found between them when compared to each other. This shows that high social physique anxiety score negatively affects the competition performance in sprinting. The present results are in accordance with the finding of Ozgur MB et al (2011), they find that as compared to non-exercisers the competitive athletes have lower social physique anxiety. It has been also noted by (Bartlewski et al., 1996 and McAuley et al., 1995) that involvement in regular exercise reduces SPA. However, McAuley and Burman (1993) found relatively high levels of SPA among elite gymnasts. These somewhat contradictory results support the contention that the part of the SPA in sport participation differs depending upon the sport under consideration. That is, SPA may be more significant for competitiors in specific sports. Competitors who participate in sports where there are strong reasons to make a positive impression on others are probable to suffer from social anxiety (Leary \& Kowalski, 1995).

\section{Conclusions}

All the components of emotional intelligence have a negative insignificant relationship with social physique anxiety and competition performance among the sprinters. The findings further found that high performance sprinters were insignificantly more emotional intelligent, and reported significantly less social physique anxiety than low performance sprinters 


\section{References}

Andrew, M.L., Tracey, J.D., Istvan, S., Istvan, K., Eva, L. and Pal H. (2010). Emotional Intelliegence and emotions associated with optimal and dysfunctional athletic performance. Journal of Sports Science and Medicin. 09, 388-392.

Austin, E.J., Saklofske, D.H., Huang, S.H. and McKenney, D. (2004). Measurement of trait emotional intelligence: Testing and crossvalidating a modified version of Schutte et al.'s (1998) measure. Personality and Individual Differences. 36(3), 555-562.

Bartlewski, E, Van Raalte, J. L, \& Brewer, B. W (1996). Effects of aerobic exercise on the social physique anxiety and body esteem of female college students. Women in Sport and Physical Activity Journal, 5(2), 49-62.

Crawford, S and Eklund, R. (2004). Social physique anxiety, reason for exercise and attitude towards exercise settings. Journal of Sport E Exercise Psychology.16(1),70-82.

Faezeh, Z., Mina, H., Elham, F., Zahra, S and Mir, H.S. (2011). A Comparison of Emotional Intelligence in Elite Student Athletes and Non-Athletes. Annals of Biological Research.2(6),179-183.

Hart, E. A., Leary, M. R., \& Rejeski, W. J. (1989). The measurement of social physique anxiety. Journal of Sport and Exercise Psychology. 11, 94-104.

Hausenblas, H. A., Brewer, B. W. and Van Raalte, J. L. (2004). Self-presentation and exercise. Journal of Applied Sport Psychology. 16: 3-18.

Kirk, B. A., Schutte, N. S. and Hine, D. W (2008). Development and preliminary validation of an emotional self-efficacy scale. Personality and Individual Differences. 45, 432- 436.

Lane, A.M., Thelwell, R. and Devonport, T.J. (2009b). Emotional intelligence and mood states associated with optimal performance. Ejournal of Applied Psychology. 5(1), 67-73.

Lane, A.M., Thelwell, R.C., Lowther, J.P. and Devonport, T. (2009c). Relationships between emotional intelligence and psychological skills among athletes. Social Behaviour and Personality: An International Journal. 37, 195-202.

Leary, M.R. (1992). Self-presentational processes in exercise and sport. Journal of Sport E Exercise Psychology. 14, 339-35.

Leary, M. R., \& Kowalski, R. M. (1995). Social anxiety. New York: Guilford Press.

Lu, F.J., Li, G.S., Hsu, E.Y. and Williams, L. (2010). Relationship between athletes emotional intelligence and precompetitive anxiety. Pub Med. 110(1), 323-38.

Meyer, B.B. and Zizzi, S. (2007). Emotional intelligence in sport: conceptual, methodological, and applied issues. In: Mood and human performance: Conceptual, measurement, and applied issues. Ed: Lane, A.M. Hauppauge, NY: Nova Science. 131-154

Mayer and Salovey. (2013). The Relationship between Emotional Intelligence, Social Physique Anxiety and Life Satisfaction in Physical Education and Sports Students. International Journal of Humanities and Social Science. 3(13), 1-5.

McAuley, E., Bane, S. M., Rudolph, D. L., \& Lox, C. L. (1995). Physique anxiety and exercise in middle-aged adults. Journal of Gerontology, 50, 229-235.

McAuley, E., \& Burman, G. (1993). The social physique anxiety scale: Construct validity in adolescent females. Medicine and Science in Sports and Exercise, 65, 1049-1053.

Ozgur, MB., Canan, K and Asci, F. (2011). An Examination of Social Physique Anxiety with Regard to Sex and Level of Sport Involvement. Journal of Human Kinetics 26 (1), 115-122. 
Petrides, K., Pita, R. and Kokkinaki, F. (2007). The location of trait emotional intelligence in personality factor space. British Journal of Psychology. 98(2), 273-289.

Schutte, N.S., Malouff, J.M., Hall, L.E., Haggerty, D.J., Cooper, J.T.,Golden, C.J. and Dornheim, L. (1998). Development and validation of a measure of emotional intelligence. Personality and Individual Differences. 25, 167-177

Schutte, N.S., Malouff, J.M., Thorsteinsson, E.B., Bhullar, N. And Rooke, S.E. (2007). A meta-analytic investigation of the relationship between emotional intelligence and health. Personalityand Individual Differences. 42(6), 921-933.

Thomas, P.R., Murphy, S. and Hardy, L. (1999) Test of Performance Strategies: Development and preliminary validation of a comprehensive measure of athletes' psychological skills. Journal of Sports Sciences. 17, 697-711.

Totterdell, P., \& Leach, D. (2001). Negative mood regulation expectancies and sports performance: an investigation involving professional cricketers. Psychology of Sport and Exercise. 2, 249-265.

Van Rooy, D.L. and Viswesvaran, C. (2004). Emotional intelligence: A meta-analytic investigation of predictive validity and nomological net. Journal of Voc. Behav. 65(1), 71-95.

Zizith, S.J., Deaner, H.R. and Hirschhorn, D.K. (2003). The Relationship Between Emotional Intelligence and Performance Among College Baseball Players. Journal of Applied Sport Psychology. 15(3), 262-269.

Mr. Devdeep Chakarvarti is Physical Education Teacher, Academic Heights Public School, Haridwar, Uttarakhand, India.

Dr. Manohar Lal is Assistant Professor, Department of Physical Education, Lovely Professional University, Phagwara, Punjab, India-144001. 